\title{
Simonetto, Patricio (2019). El dinero no es todo. Compra y venta de sexo en la Argentina del siglo XX. Buenos Aires: Biblos, p. 242.
}

\author{
Gabriela Lozano Rubello \\ gabriela.lozano.rubello@gmail.com \\ Instituto de Estudios de Género (IIEGE) Universidad \\ de Buenos Aires. CONICET, Argentina
}

Recepción: 30 Octubre 2020

Aprobación: 18 Abril 2021

Publicación: 03 Mayo 2021

\begin{abstract}
Cita sugerida: Lozano Rubello, G. (2021).
[Revisión del libro El dinero no es todo. Compra y venta de sexo en la Argentina del siglo $X X$ por P. Simonetto]. Anuario del Instituto de Historia Argentina, 21(1), e140. https://doi.org/10.24215/2314257Xe140
\end{abstract}

En 1875, en Buenos Aires se aprobó la prostitución a través del control estatal de los burdeles y posteriormente dicha iniciativa se hizo efectiva en todo el territorio nacional. Quienes trabajaban en esos lugares eran principalmente mujeres inmigrantes que huían de la pobreza y contextos de guerra en Europa. Fueron las redes del comercio sexual el espacio donde confluyeron varones y mujeres de diversas nacionalidades que encontraron en este mercado de trabajo una vía de subsistencia y construcción de vínculos. En contexto, durante la transición del siglo XIX al XX, la Argentina se encontraba en un proceso de formación de un Estado-Nación delineado por expectativas de modernización capitalista que había convocado a sectores profesionales e intelectuales a intervenir en la construcción de legitimidad de la autoridad pública, a partir del planeamiento de las nuevas instituciones y con la imposición de normas de higiene y disciplinamiento dirigidas a la clase trabajadora. 
Diversos estudios interesados en la historia social del trabajo y los estudios de género se detuvieron en el fenómeno de la venta y compra de sexo recurriendo a fuentes variadas y reponiendo diversas voces de ese pasado. A partir de dichos trabajos se reconstruyeron los vínculos entre la policía, funcionarios municipales, rufianes, higienistas, criminólogos y mujeres inmigrantes de distintas procedencias étnicas (Guy, 1994). Asimsimo, se conocieron las experiencias de las propias prostitutas en su multiplicidad de acuerdos tanto con sus vínculos sociales, como con el trabajo y sus decisiones económicas (Schettini, 2019; 2014). En este grupo de estudios se inserta el libro de Patricio Simonetto, titulado El dinero no es todo. Compra y venta de sexo en la Argentina del siglo XX (2019), publicado por la editorial Biblos.

La obra es el resultado de una investigación de largo aliento que describe las diversas formas de compraventa del sexo en el siglo XX en distintas localidades de la provincia de Buenos Aires, Argentina. Para ello, desde el campo de la historia social y los estudios de las sexualidades, Simonetto logra reconstruir piezas del proceso histórico desde una perspectiva dialéctica que brinda relevancia tanto a las subjetividades, trayectorias y condiciones específicas de los sujetos, como los sucesos que definieron al mundo político y cultural de la época.

El libro recorre distintos momentos clave de este periodo. El punto de partida es el año de 1936, cuando la Ley de Profilaxis abolió la prostitución por vez primera y el cierre temporal es el año de 1984, cuando se restituyó finalmente la prohibición en todo el territorio. A lo largo de seis capítulos, el autor explora distintas aristas del universo de la prostitución para cuestionarse dicha categoría desde un tiempo presente. Para ello aborda dos dimensiones de análisis. La primera indaga en torno a algunas de las disputas emprendidas entre el poder legislativo, policial y médico y otros sectores profesionales que participaron del devenir del mercado del sexo en el siglo XX. Esto le permite interpretar cómo funcionaron ciertas prácticas de intervención respecto al ejercicio de la sexualidad a partir de la imposición de ideales vinculados a la necesidad de imponer la idea de moral pública. En esta línea también reconstruye los sentidos y prácticas desplegadas por movimientos católicos, peronistas y sindicalistas respecto a la abolición de la prostitución e indaga en la idea del cuidado de la sexualidad masculina como el centro del imaginario nacional.

La segunda dimensión explora la diversidad de agencias, relaciones socioeconómicas y formas de ejercer y sufrir explotación y coerción por parte de mujeres y varones que de muy diversas maneras participaron del intercambio de sexo por dinero, como las propias prostitutas, los clientes y los proxenetas o rufianes.

Los testimonios que analiza Simonetto revelan experiencias de mujeres y varones provenientes de Europa y de otras ciudades latinoamericanas que a su llegada a la Argentina buscaron insertarse en la sociedad y encontraron formas de subsistencia que estaban en los márgenes de la ley. No es un dato menor que las historias registradas en el libro se sitúan en distintos puntos del país ya que dicha diversidad otorga al análisis elementos para pensar las jerarquías sociales, las formas de construcción de la identidad y las nociones respecto a la sexualidad, la moral y el placer.

Seguir los rastros de León Reiss, Motcho Goldberg, Szmelko Markus, Susana, Lucía, Martina y Marta, le exigió a Simonetto asumir como escalas de análisis no sólo el ámbito local, sino transitar entre lo nacional e internacional para acompañar a las prostitutas y proxenetas en sus viajes a la ciudad de Buenos Aires desde Varsovia, Río de Janeiro, Montevideo y Mendoza. Este trabajo con las fuentes muestra una pesquisa meticulosa sobre materiales inéditos, diarios y revistas, el registro de expulsión de extranjeros del Ministerio del Interior en los expedientes del Departamento de Histórico Judicial del Sur y del Centro de la Provincia de Buenos Aires y los legajos del Servicio Penitenciario Bonaerense. Además, se examinó un informe de 1924 que contiene entrevistas a proxenetas y prostitutas elaborado por un investigador privado y una serie de cartas que contienen demandas del cuerpo militar hacia Juan Domingo Perón, entonces Ministro de Guerra de la Nación, acerca de la instalación de burdeles patentados para evitar la homosexualidad y la masturbación entre los conscriptos. Asimismo, Simonetto indagó cartas de grupos católicos presentadas en el Congreso de la Nación Argentina con las que se buscaba detener la prohibición de la prostitución y cartas de líderes sindicales dirigidas al Ministerio del Interior de la Nación que contienen quejas sobre la abolición. 
En cuanto a la organización del texto, en el primer capítulo el argumento es que el fin del proyecto liberal argentino y el fin de la inmigración como apuesta al desarrollo, evidenció dos situaciones. La primera, que la figura del proxeneta sirvió para articular nociones de racialización en una Argentina que buscaba poner barreras a la inmigración. La segunda, que la organización de las redes de tráfico permitió ver cómo los proxenetas hacían uso de las relaciones familiares e incluso de la figura del matrimonio para obligar a las mujeres a prostituirse y apropiarse de las ganancias por la venta de sexo.

El segundo capítulo recupera las resistencias y reacciones de militares, sindicalistas, médicos, peronistas y movimientos católicos en torno al debate público vinculado a la sexualidad en el marco de la abolición de la prostitución reglamentada (1936 y 1965).

El hilo conductor del tercer capítulo responde a la pregunta acerca de cómo la aplicación de la Ley de Profilaxis afectó las prácticas y sentidos de mujeres que fueron encarceladas por ejercer la prostitución entre 1936 y 1984, periodo en el que se observó un aumento de procesos judiciales y encarcelamientos. Con expedientes judiciales y legajos de las cárceles, se reconstruyen los vínculos y las demandas de esas mujeres, los saberes se compartían de celda a celda y qué sentidos construían respecto a su identidad.

El cuarto capítulo explora las trayectorias de vida de mujeres marcadas por ejes de diferenciación como la edad, su condición de género y la clase social que trabajaban en la compra-venta de sexo en el sur de la provincia de Buenos Aires entre 1937 y 1960. Además, se describen contextos de localidades donde las actividades económicas, como el trabajo estacional y la circulación de la mano de obra masculina, definían la demanda de comercio sexual.

En el quinto capítulo se analizan testimonios de clientes convocados por la Justicia como testigos en distintos procesos penales en los que se buscaba acusar a mujeres y varones de proxenetas. Simonetto releva una trama en la cual se evidencia que el consumo de sexo o acceso al coito pago era entendido por los propios testificantes varones como un derecho natural que reafirmaba su masculinidad.

El sexto y último capítulo examina formas de intercambio de sexo por dinero en la zona norte y oeste de la Provincia de Buenos Aires durante las décadas de 1960 y 1970, periodo en el que Simonetto identifica la creación de nuevos circuitos informales de venta y compra de sexo tanto en las rutas como en zonas rurales.

Sin dudas, El dinero no es todo abre una ventana desde la cual los y las lectoras pueden seguir algunos de los debates que definieron la vida pública y el ejercicio de la sexualidad en la Argentina del siglo XX. Un significante aporte del trabajo es el haber identificado la relación entre las estructuras familiares y los recorridos de mujeres jóvenes que ingresaron a tramas de explotación, porque ello obliga a la reflexión respecto hasta dónde la condición de género, edad y clase encarnan trayectorias signadas por la desigualdad. Otro aspecto a resaltar es el lugar de la agencia aún en esas relaciones jerárquicas. En los relatos hay evidencia de que aún en los más adversos contextos las mujeres fueron capaces de desplegar solidaridad y saberes compartidos como estrategias para mejorar sus condiciones, ya sea estando en la cárcel o en burdeles informales u otros espacios.

En conclusión, la descripción y análisis que propone el libro respecto sobre las tensiones y negociaciones propias de la pertenencia de clase, género, edad y racialidad, hacen de éste una obra que contribuye a desnaturalizar la sexualidad y evidenciarla como el resultado de procesos culturales, económicos y sociales. Esta coherencia lleva a confirmar la intención del autor de mostrar que todas las formas de explotación que están asentadas en relaciones patriarcales y capitalistas son denigrantes.

Finalmente, el libro resulta una oportunidad para ampliar la comprensión de procesos económicos y sociales que tienen vigencia aún hoy en día en debates legislativos, jurídicos y periodísticos, así como en las demandas de movimientos sociales como el feminismo, y en las demandas de las propias trabajadoras sexuales en torno a la regulación de la prostitución en el plano nacional, supranacional y transnacional. 


\section{REFERENCIAS}

Guy, D. (1994). El Sexo Peligroso: la prostitución legal en Buenos Aires. Buenos Aires: Ed. Sudamericana.

Schettini, C. (2019). El dinero de las prostitutas. Trabajo sexual y circuitos inmigratorios entre Río de Janeiro y Buenos Aires (1907-1920). En J. Suriano y C. Schettini, Historias cruzadas: diálogos historiográficos sobre el mundo del trabajo en Argentina y Brasil. 1a ed. Ciudad Autónoma de Buenos Aires: Teseo.

Schettini, C. (2014). Conexiones transnacionales: agentes encubiertos y tráfico de mujeres en los años 1920. Nuevo Mundo, 28 noviembre 2014. https://doi.org/10.4000/nuevomundo.67440 